\title{
O LABORATÓRIO ESCOLAR DE CIÊNCIAS E SUAS CONTROVERTIDAS CONCEPÇÕES
}

\section{GREYZE MARIA PALAORO DEITOS}

\author{
Universidade Estadual do Oeste do Paraná - Campus Cascavel \\ E-mail: greyzepalaoro@hotmail.com
}

\section{VILMAR MALACARNE}

Universidade Estadual do Oeste do Paraná - Campus Cascavel

E-mail: vilmar.malacarne@unioeste.br

\begin{abstract}
RESUMO
Este trabalho tem como objetivo discutir a experimentação no ensino de ciências com intuito de levantar questionamentos acerca dos métodos utilizados para a realização destas práticas em laboratório de ciências. A pesquisa foi realizada com coordenadores(as) de escolas do município de Cascavel, PR onde buscou-se reconhecer qual é a compreensão destes profissionais a respeito da relação do ensino e do aprendizado com o laboratório de ciências. Realizamos também uma busca em artigos científicos e livros que tratam deste tema para compreender como os pesquisadores compreendem esta temática. Percebemos que a utilização da experimentação é de fundamental importância para o aprendizado dos conteúdos de ciências e que o papel do professor, enquanto mediador do processo de ensino e aprendizagem torna a experimentação significativa para o aluno. Contudo, visualizamos que alguns problemas de fundo conceitual foram encontrados e precisam ser revistos para a eficácia das aulas experimentais no ensino de ciências.
\end{abstract}

\section{PALAVRAS-CHAVE:}

Ensino de Ciências; Experimentação; Laboratório de Ciências.

\section{THE SCIENCE SCHOOL LABORATORY AND ITS CONTROVERSIALCONCEPTIONS}

\section{ABSTRACT}

This work aims to discuss the experimentation in science teaching in order to raise questions about the methods used to accomplish these practices in the Science laboratory. The research was conducted with coordinators of schools in the city of Cascavel, PR, where we sought to recognize the understanding of these professionals regarding the relationship between teaching and learning with the Science laboratory. We also conducted a search in scientific articles and books that deal with this topic to understand how researchers understand this theme. We perceive that the use of experimentation is of fundamental importance for the learning of the science content and that the role of the teacher, as a mediator of the teaching and learning process, makes the experimentation meaningful to the student. However, we have seen that some conceptual background problems have been found and need to be reviewed for the efficacy of experimental classes in science teaching.

\section{KEYWORDS:}

Science Teaching; Experimentation; Science Lab. 


\section{INTRODUÇÃO}

No campo do ensino de Ciências, inúmeras discussões têm acontecido com objetivo de contribuir no esclarecimento dos objetivos de se utilizar a experimentação no laboratório de ciências no ensino básico como ferramenta que propicie o aprendizado no aluno. Muitos professores concordam que o uso de aulas práticas no ensino de ciências é imprescindível, entretanto, relatam a falta de esclarecimento para que esse procedimento seja realizado de forma a agregar na formação acadêmica dos estudantes.

Por meio da inserção de aulas experimentais na disciplina de Ciências busca-se superar um ensino, que até meados do século XX considerava segundo Espinoza, (2010, p.83) que: "[...] o trabalho experimental na escola se restringia à explicação que o professor dava aos alunos para confirmar ou ilustrar seu discurso". Essa metodologia do ensino de ciências foi difundida durante séculos como modelo a ser seguido com postura centralizadora e dominadora do professor, como único detentor do saber.

Esse modelo tradicional de ensino vem sendo questionado em todas as suas dimensões metodológicas, mas aqui buscaremos enfatizar as relações impostas ao trabalho experimental no ensino de ciências para a educação básica com intuito de esclarecer eventuais erros conceituais cometidos no emprego do uso do laboratório durante as experimentações.

Segundo Pereira (2009) assim como a Ciência sofreu modificações, a função do trabalho experimental na educação científica, também passou por transformações e isso se manifesta dentro dos currículos de ciências na busca de uma ação reflexiva, fugindo dos moldes tradicionais que seguem a exposição e assimilação. Pinto, Viana e Oliveira (2013, p.92) dizem que: "Nessa perspectiva, este importante espaço de aprendizagem não pode mais ser um subterfúgio para práticas educativas antiquadas ou dogmáticas de ênfase empirista". Todo o processo metodológico de ensino de 
ciências foi alterando-se para a formação de um cidadão capaz participar criticamente da sociedade a qual faz parte.

Nesse sentido de busca pelo objetivo do uso do laboratório de ciências é que esse trabalho transcorrerá, buscando através de pesquisadores um aporte teórico para fundamentar os dados levantados sobre o uso deste ambiente escolar.

\section{Percurso Metodológico}

Dentro de diversos entendimentos sobre o ensino de ciências e experimentação, buscamos, através de uma pesquisa com os coordenadores de escolas do Município de Cascavel, PR, compreender como esses profissionais estabelecem relação entre o ensino/aprendizado dos conteúdos de ciências com o uso do laboratório.

Para este estudo, o objetivo é categorizar as concepções que os coordenadores de escolas municipais têm da experimentação no ensino de ciências como possibilidade de aprendizagem significativa.

O município de Cascavel possui 51 escolas municipais urbanas de Ensino Fundamental I, destas, 46 responderam ao questionário, obtendo um total de 55 formulários respondidos, um número maior de questionários do que de escolas, pois em algumas escolas, pela demanda de alunos, há duas coordenadoras.

A questão levantada aos coordenadores foi aberta, com possibilidade do profissional expressar livremente seu entendimento sobre o assunto: "Como você enquanto coordenador (a) compreende a relação do ensino e aprendizado com o laboratório de ciências?" Para análise das respostas, utilizamos Análise de Conteúdo de Bardin (1977), criando categorias com semelhanças, com vistas a compor uma análise mais segura. Por meio desta representatividade, buscamos compreender como a experimentação no ensino de ciências é vista pelos coordenadores de escolas do município de Cascavel. 
A primeira etapa desta análise se dá através da leitura flutuante, como nos indica Bardin (1977), é por meio desta leitura que se tem o primeiro contato com o material a ser analisado. Após inúmeras leituras, propõem-se o início da categorização dos dados obtidos através da pesquisa. Nesta fase de exploração do material, de leitura mais consistente, possibilita a categorização das informações, e organização em quadros e tabelas agrupando conforme as categorias estabelecidas durante as leituras.

Ressaltamos aqui o motivo da escolha por coordenadores escolares para esta pesquisa. No nosso município quem assume a função de coordenador de escola são os próprios professores concursados, que passam por uma prova, que avalia se possuem conhecimentos necessários para coordenar outros professores. Também entendemos que estes profissionais estão constantemente auxiliando diretamente os professores em sala de aula e suas concepções serão repassadas incondicionalmente aos colegas, daí o fato de analisarmos os coordenadores de escola.

\section{A EXPERIMENTAÇÃO NO ENSINO DE CIÊNCIAS}

O tema experimentação não é recente quando falamos a respeito de ensino de ciências, no entanto, um número ainda significativo de pesquisadores direciona seus estudos para esta área do ensino. Muitos autores como Barberá e Valdez (1996), Giordan (1999), Arruda e Laburú (2009), Espinoza (2010), Cachapuz (2011), entre outros, acreditam nos benefícios para a educação quando usado aulas experimentais na disciplina de ciências, entretanto esses mesmos autores citam inúmeras divergências quanto à abordagem e concepção de Ciência aplicada durante estas aulas. Camillo e Mattos (2014, p.125) revelam que: "Apesar da grande importância atribuída à atividade experimental, esta longe de existir um consenso entre professores e pesquisadores acerca da sua utilização, seus objetivos e métodos". Essas diferenças se devem, na maioria das vezes, por formações acadêmicas diferentes, 
concepções sobre o que é Ciência e do objetivo desta no aprendizado do educando que os professores possuem.

Sabe-se que durante muitos séculos o ensino de ciências pautou a experimentação como metodologia verificacionista, sem possibilitar a participação do aluno enquanto produtor de ciência. Esta afirmação é reforçada por Flores, Sahelices e Moreira (2009, p.80) onde dizem que: "Até final dos anos cinquenta do século passado, o ensino de laboratório se centrou principalmente em atividades verificativas discutidas nas salas de aula, abordadas nos livros texto e sugeridas em manuais de laboratório". Sendo assim, o ensino continuava a ser realizado por transmissão e assimilação, mesmo com aulas experimentais em laboratórios.

O lançamento do primeiro satélite espacial (Sputnick) ao espaço pela extinta União Soviética, em 1957, marcou o início de um conjunto de projetos, numa ampla reforma curricular no ensino de ciências nos Estados Unidos e na Europa Ocidental. Esses projetos, que ganharam força entre 1970 e 1980, inseriram no ensino a dimensão dos processos e procedimentos científicos. (PEREIRA, 2009, p.68)

Necessitando de um desenvolvimento científico, gerado pelo avanço soviético na conquista do espaço, o currículo americano de ciência se inovou, buscando estratégias alternativas às práticas tradicionais de ensino. Segundo Pereira (2009) neste período as aulas experimentais centravam-se no laboratório, e para o estudante aprender ciências ele deveria executar os experimentos de maneira semelhante à dos métodos científicos. Fernández et al (2002, p. 480) nos falam que a visão dos professores quanto ao método científico que se estruturava seguia: "[...] como uma sequência de etapas definidas, destacando o rigor do mesmo e o caráter exato dos resultados obtidos... uma visão rígida e dogmática da ciência". Os alunos eram vistos como mini cientistas, e, repetindo exatamente os passos realizados pelos cientistas nas experimentações, chegariam ao conhecimento por estes produzido.

Esta é uma visão da ciência que acredita no ensino por revelação, pois o conhecimento já estaria pronto no fenômeno a ser investigado, e ao longo da 
experimentação o conhecimento surgiria naturalmente. Configurou-se, assim, o denominado conhecimento científico por descoberta. Cachapuz et al (2011, p.73) aponta que:

Em particular, no trabalho experimental, os estudantes executam tarefas sem saber para onde caminham e que respostas hão de dar e a quê. Parece - e parece-lhes - que os conhecimentos surgem claros, óbvios e não precisam de ser interrogados e têm uma resposta que surge natural.

Contudo, este seria um modelo de ensino que não reflete a imagem da Ciência, que se baseia, não somente em dados empíricos, mas também, em fundamentações teóricas, trocas de experiência entre diversas áreas e profissionais e se mantém inserida numa sociedade geradora de influências culturais, sociais e econômicas sobre os produtos elaborados pela Ciência.

Este modelo de aprendizagem, denominado de ensino por descoberta, como visto anteriormente, assumia um modelo rígido, pré-estabelecido pelo professor ou material didático. Popularmente chama-se de 'modelo de receita', sendo as etapas esquematizadas pelo professor, que assume papel fundamental de organizador e os alunos, assumem papel de coadjuvantes, sendo executores de tarefas. Rosito (2011) fala que não é possível aprender Ciências com atividades do tipo receita, estruturadas rigidamente e aplicadas indistintamente a qualquer tipo de experimentação, ao invés disso, a experimentação deve ser embasada em reflexões pautadas em levantamentos teóricos previamente estabelecidos. Contrariando essa concepção empiristaindutivista de ensino de ciências, com práticas derivadas de generalizações que levam ao particular e que reconhece a observação como fonte de conhecimento, Rosito (2011) aponta para que:

O ensino dentro desta concepção pode desvalorizar a criatividade do trabalho científico, conduzindo os alunos a aceitar o conhecimento científico como um conjunto de verdades definitivas e inquestionáveis, além de desenvolver rigidez e intolerância em relação a opiniões diferentes. (ROSITO, 2011, p.155) 
Embora contestada por diversos pesquisadores, esta concepção ainda se encontra nos bancos escolares. Flores, Sahelices e Moreira (2009, p.81) acreditam que: "Sem dúvida, muitos estudantes pensam que o propósito do trabalho de laboratório é seguir instruções e obter a resposta correta, pelas ideias que se concentram de manipular instrumentos mais do que manejar ideias". Estas atividades se concentram na reprodução e não no questionamento e busca por soluções.

Dentro deste entendimento, a prática pedagógica perde grande parte da sua motivação inicial, de auxiliar no processo de ensino/aprendizagem dos alunos. Barberá e Valdés (1996) expõem que a dimensão especial da experimentação se perde nesse tipo de construção, e torna sem sentido a prática, onde esforços significativos são envolvidos na sua realização e não levam ao processo de aprendizagem da ciência.

Contrariando o modelo de experimento visto até agora, inúmeros pesquisadores debruçaram esforços na busca de uma prática experimental que trouxesse aos alunos um desenvolvimento cognitivo relevante, deixando de possuir papel coadjuvante para ser ator principal na construção do seu conhecimento. Espinoza (2010) lembra que é necessário observar quais as possibilidades que o experimento oferece, que com uma simples leitura de um texto não poderia obter-se os mesmos conhecimentos. A prática experimental com fim nela mesma deixa de possibilitar diversos conflitos cognitivos que podem ser explorados durante a aula. Cachapuz et al (2011, p.78) nos diz que: "O que está em causa é evitar que a atividade científica seja apenas apresentada sob a forma formal final de informações ou mesmo de um mero conhecimento adquirido, sem a necessária compreensão de como se lá chegou", ou seja, evitar uma educação mecânica onde a reflexão não se faz presente, apenas a repetição.

O professor, devido às atribuições próprias de sua profissão, é quem orienta e conduz a prática educativa em sala de aula, por isso, muitas vezes é questionado como este estabelece metodologicamente os conteúdos curriculares que estão a cargo de 
cada ano escolar. Cachapuz et al (2011, p.100) alerta que: "O que nos parece de sublinhar é, pois, a necessária mudança de atitude dos professores no sentido de ultrapassarem a aceitação fácil de um empirismo clássico e ingênuo, concebendo a ciência como uma simples descoberta [...]". A ciência é muito mais que descoberta, é um trabalho minucioso, demorado, feito na coletividade e embasado em teorias e não só em observações isoladas e repetidamente.

Na busca por valorizar um ensino de Ciências participativo, Marsulo e Silva (2005, p.8) nos falam que: "Partindo do foco da observação, o aluno vivencia, 'vê' o fenômeno com ideias e sentidos, utilizando a sua iniciativa, originalidade, inquietações e curiosidade para especular." Assim sendo, o aluno deixa de ser passivo e se torna ativo no seu próprio aprendizado, onde ele próprio estabelece relações com o já conhecido e com o novo conhecimento, a partir do problema a ser solucionado, que está sendo construído.

O ponto de partida não é 'um' problema, mas parte-se 'do' problema que necessita ser percebido para que o sujeito assuma e tome conta do meio real. Neste caso, o contexto sócio, econômico e cultural vai determinar a forma como será vista a situação problemática e as discussões sobe essa questão gerarão em torno da construção do problema a ser resolvido. (MARSULO e SILVA, 2005, p.7)

Sendo assim, o primeiro passo para a realização da experimentação é o reconhecimento do problema a ser solucionado. Sem um problema, um questionamento, uma dúvida, não há necessidade de se fazer uma pesquisa ou experimento para encontrar uma solução. Anderson (1976), citado por Barberá e Valdés (1996, p.367) diz que: “O trabalho de laboratório é o lugar onde uma pessoa ou um grupo empreende a tarefa humana de examinar e tentar proporcionar uma explicação aos fenômenos naturais". Nesta tentativa de explicações algumas hipóteses devem ser lançadas, Cachapuz et al (2011, p. 92) fala que: “A hipótese tem um papel de articulação e de diálogo entre as teorias, as observações e as experimentações, servindo de guia à própria investigação". Isso nos remete a indissociabilidade da teoria 
e da prática, uma dando fundamentação à outra, até porque não existe ciência sem teoria. Desta forma, também o ensino de ciências deve proporcionar a relação entre a teoria e o experimento, auxiliando na solução do problema, verificando o que já existe produzido sobre o assunto, bem como levantando hipóteses para encontrar posteriormente fazer o experimento.

Nesse processo, de uma atividade experimental investigativa, o aluno será levado a fazer reflexões, eliminar, argumentações, organização, diálogo, inferências entre outros fatores que influenciam diretamente a experimentação. O sentido da experimentação no ensino de ciências é de que os alunos compreendam e envolvamse com o trabalho científico, contudo, não seriam possíveis práticas idênticas às realizadas pelos cientistas, por condicionantes de tempo, equipamentos, conhecimentos teóricos entre outros fatores. Rosito (2011, p. 152) fala que: “[...] a experimentação, desempenha um papel fundamental, pois possibilitam o aluno uma aproximação do trabalho científico e melhor compreensão dos processos de ação das ciências". Ainda nesse contexto das possibilidades contidas na experimentação, Borges (2002) afirma que o laboratório pode proporcionar aos alunos diversas oportunidades de refletirem sobre suas hipóteses, questionando suas abordagens e se seus resultados foram coerentes aos processos utilizados.

Deve-se pretender, antes, que os alunos aprendam que a ciência é uma luta constante e difícil na busca de mais verdades (não confundir com certezas) e os professores devem encorajar os alunos ganhar confiança nas suas conjecturas racionais, para serem capazes de refutar, por em causa as hipóteses de seus pares, e em última análise, sejam capazes de vivenciar de algum modo o sentido e o espírito da própria construção do conhecimento científico. (CACHAPUZ et al, 2011, p.82)

A experimentação permite ao professor e ao aluno uma aproximação com os conceitos e processos científicos de maneira dinâmica e interativa. Neste modelo de prática, o aluno se torna consciente do trabalho experimental que está realizando. 0 desenvolvimento cognitivo se favorece deste modelo de atividade, onde é constante 
a reflexão, interação, justificação, raciocínio e conclusão, chegando mais rapidamente ao desenvolvimento efetivo com a aprendizagem dos conteúdos estabelecidos curricularmente pelo sistema formal de ensino.

\section{ANÁLISE DOS DADOS}

A coleta dos dados se deu em duas etapas. Iniciamos a coleta numa reunião dos coordenadores do município, onde a secretária destinou um tempo para o preenchimento do questionário. Posteriormente, entramos em contato com os coordenadores faltantes da reunião e individualmente coletamos os dados.

Dentre os 55 questionários coletados, excluiu-se os branco, totalizando 44 questionários analisados, que após codificação e categorização das respostas, seguindo a teoria de Bardin (1977), agrupamos os dados dos coordenadores segundo as semelhanças de suas respostas.

Quadro 1: Respostas dos coordenadores de escola. Fonte: dados da pesquisa.

\begin{tabular}{|c|l|}
\hline Coordenador(a) de escola & $\begin{array}{l}\text { Relação de ensino/aprendizado e o uso do laboratório de } \\
\text { Ciências. }\end{array}$ \\
\hline $\mathbf{2 0}$ & $\begin{array}{l}\text { O laboratório serve para pôr em prática o que se aprende em } \\
\text { sala de aula; }\end{array}$ \\
\hline $\mathbf{1 5}$ & $\begin{array}{l}\text { A prática em laboratório proporciona melhor apropriação dos } \\
\text { conteúdos; }\end{array}$ \\
\hline $\mathbf{1}$ & $\begin{array}{l}\text { Aprender os processos e métodos das Ciências; compreender } \\
\text { às aplicações da ciência e compreender as CTS; }\end{array}$ \\
\hline $\mathbf{1}$ & $\begin{array}{l}\text { Fundamental para a formação do sujeito... permitem o } \\
\text { conhecimento de si e do meio; }\end{array}$ \\
\hline $\mathbf{1}$ & Aprendizado na prática \\
\hline $\mathbf{2}$ & $\begin{array}{l}\text { Experienciar, levantar hipóteses, argumentar e compreender; } \\
\text { O nível de ensino do fundamental I necessita do concreto } \\
\text { para sistematizar o conhecimento; }\end{array}$ \\
\hline $\mathbf{1}$ & Experimentos do cotidiano dos alunos \\
\hline $\mathbf{1}$ & Teoria e prática andarem juntas \\
\hline $\mathbf{1}$ &
\end{tabular}


Esta análise do ensino de ciências entende que o professor tem papel essencial na transformação das visões deformadas que circundam o meio escolar. Entretanto reconhecemos a necessidade de formação específica que reorganize essa forma de pensar e agir do docente. Cachapuz et al (2011, p.37) afirma que para a mudança de concepções nos professores há: "[...] necessidade de estabelecer no que se pode compreender como uma imagem basicamente correta sobre a natureza da ciência e da atividade científica, coerente com a epistemologia atual". Construindo assim, um ensino de ciências distante da educação científica meramente transmissiva, gerando uma visão empobrecida da ciência e desinteresse nos alunos que viam dificuldades de 'decorar' leis e conceitos criados pela ciência.

Através das respostas pode-se compreender que a concepção de ensino de ciências com o uso do laboratório escolar se mantém praticamente inalterado em relação ao apontado pelos autores já citados anteriormente. Opiniões como: "O laboratório serve para pôr em prática o que se aprende em sala de aula"; "De fundamental importância, pois através do laboratório o aluno pode compreender também na prática o que já fora exposto teoricamente"; "Entendo como a sistematização prática dos conteúdos estudados", apontam para a dissociação entre teoria e prática, onde a prática em laboratório tem função específica de comprovação dos conteúdos teoricamente vistos em sala de aula.

Outra preocupação apresentada pelos pesquisadores da área é o fato de que a teoria e a prática devem estar concomitantemente presentes na experimentação. Borges (2002, p. 16) lembra que: "Não se trata, pois, de contrapor o ensino experimental ao teórico, mas de encontrar formas que evitem essa fragmentação[...]". Nas respostas obtidas dos coordenadores essa dissociação fica muito clara, onde a 
teoria é vista em sala de aula como conteúdo científico relevante, e a prática se apresenta com intuito da comprovação ou ilustração.

O ensino de ciências busca a superação deste modo de entender as atividades laboratoriais, assim, Rosito (2011) nos lembra que é necessário construir uma relação forte entre o que foi trabalhado em sala de aula e o que está sendo realizado no laboratório, pois para ela as atividades experimentais realizadas nesse espaço necessitam de uma fundamentação teórica que busca auxiliar os processos de investigação, na formulação de hipóteses e análise dos resultados.

Também dissemos que os cientistas detêm um saber que lhes permite formular as perguntas que orientam seu trabalho, criar os instrumentos para um experimento, imaginar quais as possíveis variáveis que teria sentido criar, reconhecer que resultados são coerentes com o conhecimento acumulado. (ESPINOZA, 2010, p.88)

Partindo desse pensamento, de que teoria e prática são indissociáveis, Arruda e Laburú (2009) nos remetem ao fato de que cientista algum vai ao laboratório sem saber o que procura descobrir, estando embasado teoricamente para formulação de hipóteses e caminhos a seguir, e consequentemente seus resultados também serão explicados à luz destas teorias. Na pesquisa em questão apenas um coordenador relatou que: "Excelente, pois torna-se possível teoria e prática andarem juntas" (grifo nosso), opondo-se a maioria que a credita ser o laboratório um espaço destinado a visualização do que foi aprendido na teoria em sala de aula. A fala do coordenador pode ser confirmada por Cachapuz et al (2011, p.95) onde diz que: "[...] a experimentação exige uma grande e cuidadosa preparação teórica e técnica, precedida e integrada num projeto que a orienta". Fortalecendo a importância do estabelecimento de relações entre teoria e prática do início ao fim da pesquisa.

Outro dado observado na pesquisa foi de que 15 coordenadores acreditam que as aulas práticas em laboratório de Ciência auxiliam no aprendizado dos conteúdos trabalhados. Vale ressaltar que pode se considerar unânime a utilização do laboratório 
de Ciências como auxiliar do processo de ensino e aprendizagem. Porém, é imprescindível indicar as metodologias utilizadas durante a experimentação, pois essa é o marco divisor entre um efetivo aprendizado e uma prática que não se sabe o que se quer descobrir, muito menos seus encaminhamentos.

Acredita-se, segundo Giordan (1999), que a aprendizagem das ciências naturais dependem de uma abordagem experimental, pois os fenômenos naturais, investigados por ela, possuem uma organização do conhecimento preferencialmente nos entremeios da investigação. Quando se fala preferencialmente, entende-se que nem todo conhecimento científico poderá ser desenvolvido num laboratório escolar de ciências, devido às suas limitações físicas, de equipamentos e também de pessoal capacitado para auxiliar tais experimentações.

A ideia predominante entre os professores de Ciências é de que as atividades experimentais são essenciais para um bom ensino. Mesmo assim, não existe um consenso acerca dos objetivos das atividades experimentais que vão desde motivação, desenvolvimento de habilidades específicas de laboratório, aprofundamento dos conhecimentos científicos, até o desenvolvimento de atitudes científicas. (ROSITO, 2011, p.160)

Tanto para teóricos como na pesquisa realizada neste trabalho fica evidenciado que as aulas experimentais auxiliam sim no processo de ensino/aprendizagem, contudo, como vimos nos autores citados, faz-se necessário uma problematização perante a experimentação que está sendo proposta permitindo uma reorganização conceitual que possibilitará a construção de um novo conhecimento.

Entre os entrevistados podemos citar dois coordenadores que mais aproximaram suas respostas àquelas sugeridas pelos pesquisadores. Tais falas apontam para: "As aulas no laboratório de ciências contribuirão na apropriação dos conteúdos científicos, pois é um recurso. Os alunos poderão experienciar, levantar hipóteses, argumentar e compreender..."; a outra fala diz que: "Relações que possam possibilitar adquirir conhecimento científico. Aprender os processos e métodos das ciências; compreender as aplicações da ciência, especialmente as relações entre 
ciência e sociedade e ciência - tecnologia- sociedade". Segundo Borges (2002) o que se torna necessário na experimentação no ensino de ciências não é a exclusiva manipulação de objetos e artefatos concretos, mas sim, um envolvimento comprometido na busca de soluções aos problemas colocados inicialmente. Ou seja, o que o ensino de ciências busca através da experimentação, é uma reflexão dos procedimentos e processos pelos quais a prática experimental passa.

A Ciência enfrentou inúmeros desafios para se constituir como conhecemos hoje. Passou de uma Ciência elitista, individualista, imparcial, para uma Ciência que faz parte da sociedade que a constitui. Cachapuz et al (2011, p.28) reforça a importância de vincular a ciência e a tecnologia com a sociedade e diz que: "A recuperação desses aspectos históricos e de relações Ciência - Tecnologia - Sociedade - Ambiente (CTSA)...pode contribuir para desenvolver à aprendizagem das ciências a vitalidade e relevância do próprio desenvolvimento científico[...]." Isso se deve pela inclusão da Ciência na sociedade que a originou, todos devem ter conhecimento de suas práticas, participar nas tomadas de decisões tendo uma visão crítica e consciente sobre as ações da Ciência em nossa sociedade.

Não poderíamos deixar de citar a indiscutível importância do professor no processo da experimentação. É necessário que o professor tenha clareza sobre o que pretende atingir com o uso da prática experimental no laboratório de Ciências. Proporcionar que os alunos testem suas próprias hipóteses, reflitam criticamente sobre o problema levantado, planejem suas ações de forma a produzir resultados confiáveis, são algumas possibilidades que o professor pode atingir com a experimentação.

Segundo Pinto, Viana e Oliveira (2013, p. 920 "[...] os professores devem estar atentos e buscar novas formas de abordar este espaço, o qual deve aflorar nesses profissionais a cientificidade que tem sido tão esquecida". Ou seja, evitar práticas 
ingênuas e mecânicas, proporcionar a formação de um cidadão consciente das escolhas que irá fazer, comprometido conscientemente com a sociedade a que pertence, sabendo argumentar e questionar suas posições sobre a Ciência.

Não é intenção deste artigo, culpabilizar professores por metodologias inadequadas na prática em laboratório de ciências, apenas apresentar reflexões e possibilidades de romper com o método empirista-indutivista, embasado em ideias positivistas, reconhecendo oportunidades diferentes para ampliar a aprendizagem dos alunos.

Muito desse entendimento de que o objetivo do laboratório é "Verificar e comprovar leis e teorias" (BORGES, 2002, p.16) ocorre pela formação inicial deficitária no ensino de Ciências e principalmente na prática laboratorial. Assim sendo, o professor busca em suas próprias experiências, enquanto aluno ou buscando em fontes alternativas, metodologias que possibilitem a existência dessas práticas dentro de seu fazer docente.

Cabe, é claro ao professor, a busca pelo aprendizado de novas possibilidades de práticas pedagógicas no laboratório de Ciências, como também aos representantes das secretarias de educação dos municípios ofertarem cursos de formação continuada que esclareçam a concepção de ensino de Ciências bem como traga propostas embasadas teoricamente para o uso do laboratório escolar, bem como fornecendo condições estruturais e de materiais para que elas possam se efetivar.

A partir destes relatos, é possível perceber que existe a necessidade de desenvolver junto aos professores uma visão integral para o ensino de ciências e a aprendizagem no laboratório. Flores, Sahelices e Moreira (2009, p.103) reforçam a necessidade de questionar a prática do professor no laboratório de ciências e dizem que: 
O laboratório fornece uma oportunidade para integrar aspectos conceituais, procedimentais e epistemológicos dentro de enfoques alternativos que podem permitir a aprendizagem dos estudantes com uma visão construtivista através de métodos que implicam a resolução de problemas, os quais fornecem a experiência de envolver-se com os processos das ciências e afastar-se progressivamente da concepção errônea chamado e concebido "Método Científico".

Pode-se dizer que a prática docente e suas concepções epistemológicas, durante todo processo escolar, mas aqui reduzido ao uso do laboratório de Ciências, tem função de produzir o desenvolvimento cognitivo dos alunos, para que esses se apropriem dos conhecimentos científicos necessários para se tornar um cidadão consciente e crítico, capaz de opinar e argumentar sobre suas escolhas.

\section{CONSIDERAÇÕES FINAIS}

Este artigo visou refletir criticamente sobre a concepção de uso da experimentação no ensino de ciências na educação básica. Para tanto, selecionamos autores da área que nos dessem possibilidades argumentativas para problematizar as práticas experimentais no ensino de ciências.

Chegamos a um resultado um tanto preocupante, onde um percentual significativo de coordenadores ainda acredita que a função do laboratório de ciências se restringe a ilustrações de conteúdos estudados teoricamente em sala de aula. Arruda e Laburú (2009), numa pesquisa com professores do Magistério e de Ciências da região de Londrina - PR, chegaram a três tipos básicos de objetivos para a experimentação, que em muito se assemelha com os resultados da nossa pesquisa, entre eles: serve para comprovar a teoria, facilitar a compreensão do conteúdo e desperta a curiosidade. Apontando os objetivos a uma visão tradicional de educação e do uso do laboratório.

Embora o conceito de experimentação no ensino de ciências, há décadas, vem sendo discutido, e reelaborado, ainda se faz presente uma compreensão inadequada para estas práticas nas aulas de ciências. Cachapuz et al (2011) sistematiza possíveis 
deformações no ensino de ciências, algumas delas podem ser vistas nos trechos relatados pelas coordenadoras. Desta forma, podemos aludir à necessária formação docente de tais profissionais, para que os equívocos conceituais ainda presentes no discurso destes profissionais sejam sanados.

O objetivo do laboratório de ciências, como vimos nos dados da pesquisa, ainda necessita de sistematização, razão pela qual novos estudos e novas práticas docentes são necessárias para transformar essa visão tradicionalista, em busca de uma renovação do ensino de ciências, e fazendo parte dele, o uso do laboratório escolar.

Não foi a intenção, culpabilizar professores por metodologias inadequadas na prática em laboratório de ciências, apenas apresentar reflexões e possibilidades de romper com o método empirista-indutivista, embasado em ideias positivistas, reconhecendo oportunidades diferentes para ampliar a aprendizagem dos alunos. Até pelo fato de não existir um método universal que possa representar todas as práticas científicas, cada experimentação tem sua especificidade que precisa ser respeitada para efetivação do experimento. 


\section{REFERÊNCIAS}

ARRUDA, S. de M.; LABURÚ, C. Considerações sobre a função do experimento no ensino de ciências. In: NARDI, R. (org). Questões atuais no ensino de Ciências. 2a ed. São Paulo: Escrituras Editora. p. 59 - 66. 2009.

BARBERÁ, O.; VALDÉS, P. El trabajo práctico em La enseñanza de lãs ciencias: una revisión. Enseñanza de lãs ciencias. v. 14, n. 3, 1996.

BARDIN, L. Análise de conteúdo. Tradução Luís Antero Reto; Augusto Pinheiro. São Paulo: Edições 70, 1977.

BAROLLI, E.; LABURÚ, C. E.; GURIDI, V. M. Laboratorio didáctico de ciências: caminos de investigación. Revista Electrónica de Enseñanza de lãs Ciencias. v.9, n.1, 2010.

BORGES, A. T. Novos rumos para o laboratório escolar de ciências. Cad. Brás. Ens. Fís. V.19, n. 3, 2002.

CACHAPUZ, A. et al. A necessária renovação do ensino de ciências. 3a ed. São Paulo: Cortez, 2011.

CAMILLO, J.; MATTOS, C. R. de. A experimentação no ensino de ciências: reflexões a partir da Teoria da Atividade. In: MAGALHÃES JUNIOR, C. A. de O.; LORENCINI JUNIOR, A.; CORAZZA, M. J. (orgs). Ensino de ciências: múltiplas perspectivas, diferentes olhares. Curitiba: CRV., 2014.

ESPINOZA, A. M. Ciências na escola: novas perspectivas para a formação dos alunos. São Paulo: Ática, 2010.

FERNÁNDEZ, I. et al. Visiones deformadas de La ciencia transmitidas por La enseñanza. Enseñanza de las ciencias. Enseñanza de las Ciencias. v. 20, n.3, 2002.

FLORES, J.; SAHELICES, M. C. C.; MOREIRA, M. A. El laboratório en la enseñanza de las ciencias: una visión integral en este complejo ambiente de aprendizaje. Revista de Investigación. v. 33, n. 68, 2009.

GIORDAN, M. O papel da experimentação no ensino de ciências. In: II ENCONTRO NACIONAL DE PESQUISA EM EDUCAÇÃO EM CIÊNCIAS - ENPEC, 1999, Valinhos. Anais do evento São Paulo, 1999. Disponível em http://fep.if.usp.br/ profis/arquivos/iienpec/Dados/trabalhos/A33.pdf. Acesso em 23 de novembro de 2016.

MARSULO, M. A. G.; SILVA, R. M. G. da. Os métodos científicos como possibilidade de construção de conhecimentos no ensino de ciências. Revista Electrónica de Enseñanza de las Ciencias. v. 4, n.3, 2005. Disponível em: http://reec.uvigo.es/volumenes/volumen4/ART3_Vol4_N3.pdf. Acesso em 23 de agosto de 2016. 
PEREIRA, J. E. Professores de ciências naturais: necessidades formativas para ensinar a medir em trabalhos práticos e experimentais. 2009.168 f. Dissertação (Mestrado em Educação) - Universidade Federal do Rio Grande do Norte, Natal.

PINTO, V. F.; VIANA, A. P. P.; OLIVEIRA, A. E. A. Impacto do laboratório didático na melhoria do ensino de ciências e biologia em uma escola pública de Campos dos Goyatacazes/RJ. Revista Conexão. v. 9, n. 1, 2013. Disponível em http://www.revistas2uepg.br/index.php/conexao. Acesso em 15 de setembro de 2016.

ROSITO, B. A. O ensino de ciências e a experimentação. In: MORAES, R. (org). Construtivismo e ensino de ciências: reflexões epistemológicas e metodológicas. 3 ạ ed. Porto Alegre: EDIPUCRS, 2011. 